\title{
Efficacy and safety of tacrolimus vs
}

\section{cyclophosphamide in the therapy of patients with idiopathic membranous nephropathy: a meta- analysis}

This article was published in the following Dove Press journal:

Drug Design, Development and Therapy

\author{
Wenshan Lin ${ }^{1, *}$ \\ Hong-Yan $\mathrm{Li}^{2, *}$ \\ Shujun Lin' \\ Tianbiao Zhou' \\ 'Department of Nephrology, The Second \\ Affiliated Hospital of Shantou University \\ Medical College, Shantou, People's \\ Republic of China; ${ }^{2}$ Department of \\ Nephrology, Huadu District People's \\ Hospital of Guangzhou, Southern Medical \\ University, Guangzhou, People's Republic \\ of China
}

*These authors contributed equally to this work
Correspondence: Tianbiao Zhou

Department of Nephrology, The Second Affiliated Hospital, Shantou University

Medical College, No. 69 Dongsha Road, Shantou 5I504I, People's Republic of China

Tel +86I36704025I6

Email zhoutb@aliyun.com
Background: As one of the therapeutic drugs for idiopathic membranous nephropathy (IMN), tacrolimus (TAC) has not been fully vindicated for its efficacy and tolerability. A meta-analysis was performed to detect the efficacy and safety of TAC plus glucocorticoid vs cyclophosphamide (CTX) plus glucocorticoid in therapy of patients with IMN.

Methods: A literature search with a pre-defined search strategy was conducted using English databases (PubMed, EMBASE, ClinicalKey and the Cochrane Library) and Chinese databases (China National Knowledge International, Wanfang, Chinese Scientific Journal Database (VIP)) from inception to Nov 19, 2018. Any high-quality randomized controlled trials (RCTs) comparing the effectiveness or safety of TAC with CTX in IMN patients were included. Data were extracted by two authors independently and analyzed using RevMan 5.3. Results: Four randomized controlled studies were included. In this analysis, we did not find that the statistically significant difference between TAC and CTX groups on 6-month and 12month treatment complete remission (CR) was evident (6-month: $\mathrm{OR}=1.53$, 95\% CI: 0.85 2.76, $P=0.15$; 12-month: $\mathrm{OR}=2.17,95 \% \mathrm{CI}: 0.56-8.44, P=0.27)$. But TAC had better 6month total remission (TR; total CR plus partial remission [PR]) than CTX (6-month: $\mathrm{OR}=2.62,95 \% \quad \mathrm{CI}: 1.38-4.96, \quad P=0.003 ;$ 12-month: $\mathrm{OR}=1.74,95 \%$ CI: $0.29-10.48$, $P=0.54)$, and got a lower proteinuria after 6-month treatment $(\mathrm{OR}=-0.80,95 \% \mathrm{CI}:-1.53$ to $-0.07, P=0.03$ ). TAC had a lower incidence rate on leucopenia than CTX, but had a tendency towards higher blood creatinine. In the meantime, tremor in TAC group was higher than that in CTX group. The differences on other adverse effects such as gastrointestinal syndrome, infection, herpes zoster, hypertension, liver function disorder and hyperglycemia were also analyzed. However, none of them were statistically significant.

Conclusion: TAC treatment could get high value of TR and had low value of proteinuria level when compared with those in CTX on 6-month treatment in therapy of patients with IMN.

Keywords: tacrolimus, idiopathic membranous nephropathy, complete remission, CR, total remission, TR, meta-analysis

\section{Introduction}

Membranous nephropathy is one of the commonest causes of adult nephrotic syndrome (NS), and its pathological features are observed as glomerular capillary basement membrane thickening by a light microscopy, IgG and C3 planting in capillary wall by immunofluorescence staining and immune complexes depositing in the subepithelial layer by an electron microscopy. Membranous nephropathy can be secondary to 
many factors like neoplasms, infections, drugs, poisons and autoimmune diseases. But there are still four-fifths of whom cannot find the causes, defined as idiopathic membranous nephropathy (IMN). ${ }^{1}$

About 30 50\% IMN has eventually progressed to chronic renal failure or ESRD after 10 15 years later, especially those with massive proteinuria. ${ }^{2}$ Complete remission (CR) of NS is a reliable predictor of functioning kidney and patient survival and even partial remission (PR) can improve the prognosis significantly. ${ }^{3}$ Unfortunately, the trouble is the unsatisfactory therapeutic effect of treatment in IMN at present. Recommended by Kidney Disease: Improving Global Outcomes (KDIGO) 2012 guidelines, ${ }^{4}$ for those who cannot achieve remission after 6 weeks of conservative therapy, the alternate, periodic treatment of alkylating agents and like CTX or chlorambucil in combination with methylprednisolone, known as the Ponticelli Regimen, has been proved to effectively achieve remission of NS and prevent IMN patients from ESRD, which grants it the priority for the regimen of IMN. However, on no account can we ignore the severe adverse reactions such as myelotoxicity and reproductive toxicity. It seems good news that a boom of new-onset immunosuppressants followed as the efforts of scholars. Studies have shown that calcineurin inhibitors (CNI) may be excellent in induction of remission. ${ }^{5,6}$ Of them, TAC has become a magnet, showing its potential advantage of efficiency and hypotoxicity in improving the remission rate of IMN. TAC was first used in the therapy of NS in 1990 and has ever been used for prevention of graft rejection after organ transplantation. ${ }^{7}$ TAC has been found to be able to alleviate the damage of podocytes and reduce proteinuria. For one thing, it can increase the survival of podocytes through inducing the secretion of podocin and synaptophysin as well as fixing the heterotopic distribution of actin cytoskeleton. Besides, TAC also induces pro-apoptotic molecules like Bcl-xL, caspase 3, and inhibits anti-apoptotic molecules like Bax, PRAP. ${ }^{8}$ Actually, a cloud of smoke is floating over the battlefield of superiority between TAC and CTX, and a high-quality meta-analysis is essential. Due to uncertain conclusions of previous meta-analysis, we evaluated the efficacy and safety of TAC in IMN with more stringent inclusion criteria by using Modified Jadad scores to screen out the high-quality clinical trials.

\section{Materials and methods}

\section{Search strategy}

The systematic searches were performed into both English databases like the Cochrane Library, Embase and PubMed, and Chinese databases like Chinese National Knowledge International, Wanfang, Chinese Scientific Journal Database (VIP) and Chinese Biology Medicine up to Nov 19, 2018, using the search terms: (tacrolimus OR FK506 OR TAC) AND (idiopathic membranous nephropathy OR membranous nephropathy OR membranous glomerulonephropathy OR IMN OR MN). We also checked the references cited in the recruited articles for additional reports.

\section{Inclusion and exclusion criteria Inclusion criteria}

The inclusion criteria for this study were as follows: (1) study type: randomized controlled trials, randomized crossover studies and prospective studies; (2) object of the study: all patients with IMN regardless of race; (3) interventions: TAC for treatment; (4) baseline information: TAC was compared with CTX; and (5) outcome: efficacy or safety.

\section{Exclusion criteria}

Exclusion criteria for the study were as follows: (1) Case reports, reviews, letters, systematic reviews and meta-analysis; (2) studies about the same therapeutic regimen on both arms; (3) studies including the use of agents with unknown ingredients and additional effects like traditional Chinese medicine.

\section{Outcome measures}

Efficacy of TAC: complete remission (CR), total remission (TR; total CR plus partial remission [PR]), relapse rate, proteinuria, serum albumin, serum creatinine, mean time to remission and estimated glomerular filtration rate (eGFR).

Safety of TAC: adverse effects like gastrointestinal syndrome, infection, herpes zoster, leucopenia, blood creatinine increased, tremor, hypertension, liver function disorder, hyperglycemia, gouty arthritis and so on.

\section{Data collection and quality assessment}

By browsing the titles and abstracts of the included studies and reading the full text, duty of screening out possible relevant literatures was assigned to two reviewers with the predetermined inclusion criteria. Discordant opinions were discussed and resolved by other reviewers. Only randomized controlled trials, randomized crossover studies and prospective studies relating to TAC treatment vs CTX treatment were allowed entry. All the trials were evaluated with the Modified Jadad Scale ${ }^{9}$ by two investigators independently in terms of randomization, allocation concealment, blind method, integrity of follow-up. Specific for this strategical the scale 
includes undermentioned and main content: 1. Randomization: (1) The method of randomization was described with detailed description, such as using a table of random numbers, (2 points); (2) The study was described as randomized trials without any details (1 point); (3) Not randomized or inappropriate method of randomization, such as grouping patients according to different characteristics of them (0 point). 2. Allocation concealment: (1) The method of allocation concealment was described and it was appropriate, such as using sealed envelopes (2 points); (2) The study was described as using allocation concealment but without any details (1 point); (3) Not described the method of allocation concealment (0 point). 3. Double blind method: (1) The method of double blind method was described and it was appropriate, so neither the subjects nor the researchers were aware of the grouping of experiments (2 points); (2) The study was described as using double blind method but without any details (1 point); (3) Open-label or inpropriate method of blinding ( 0 point). 4 . Withdrawals and dropouts: A description of withdrawals and dropouts (1 point); (2) Not described the follow-up ( 0 point). Only those trials scored more than 3 can be included in this study.

\section{Statistical analysis}

The data were extracted from the included literatures, and Review Manager Version 5.3 software was used to pool the results. Heterogeneity was quantified using $\mathrm{I}^{2}$ statistics and explored for all the meta-analyses. On the basis test of the heterogeneity, when the $P$-value $\geq 0.1$, a fixed effect model was used. Otherwise, the results were pooled using a random effects model. Continuous data were expressed using weighted mean differences (WMDs), and binary data were expressed using the odds ratio (OR). 95\% confidence intervals (95\% CI) with the Mantel-Haenszel (MH) method were counted for the included studies. $P$-value $<0.05$ was regarded as statistical significance.

\section{Results}

\section{Search results}

In this meta-analysis, three randomized controlled trials in four publications, ${ }^{10-13}$ totally involving 199 patients, were related to TAC vs CTX for IMN (Figure 1). All the studies compared TAC plus glucocorticoids with CTX plus glucocorticoids. In 2 studies, the dosage of TAC was given $0.1 \mathrm{mg} /$ (kg·day) initially and adjusted to a whole blood trough level between 5 and $10 \mathrm{ng} / \mathrm{mL}$, with CTX given $100 \mathrm{mg} /$ day in one study and $2 \mathrm{mg} /(\mathrm{kg} \cdot$ day $)$ in the other. Another study started with TAC at a dosage of $1 \mathrm{mg} /$ day for 1 week and then at an alternative dosage of $1 \mathrm{mg}$ one day and $2 \mathrm{mg}$ the other, maintaining the whole blood concentration with a target of 2-4 ng/mL, and the CTX group was administrated CTX 750 $\mathrm{mg} / \mathrm{m}^{2}$. Among them, the prospective, parallel and controlled trial from Chen et $\mathrm{al}^{10}$ scored 5 points, performing

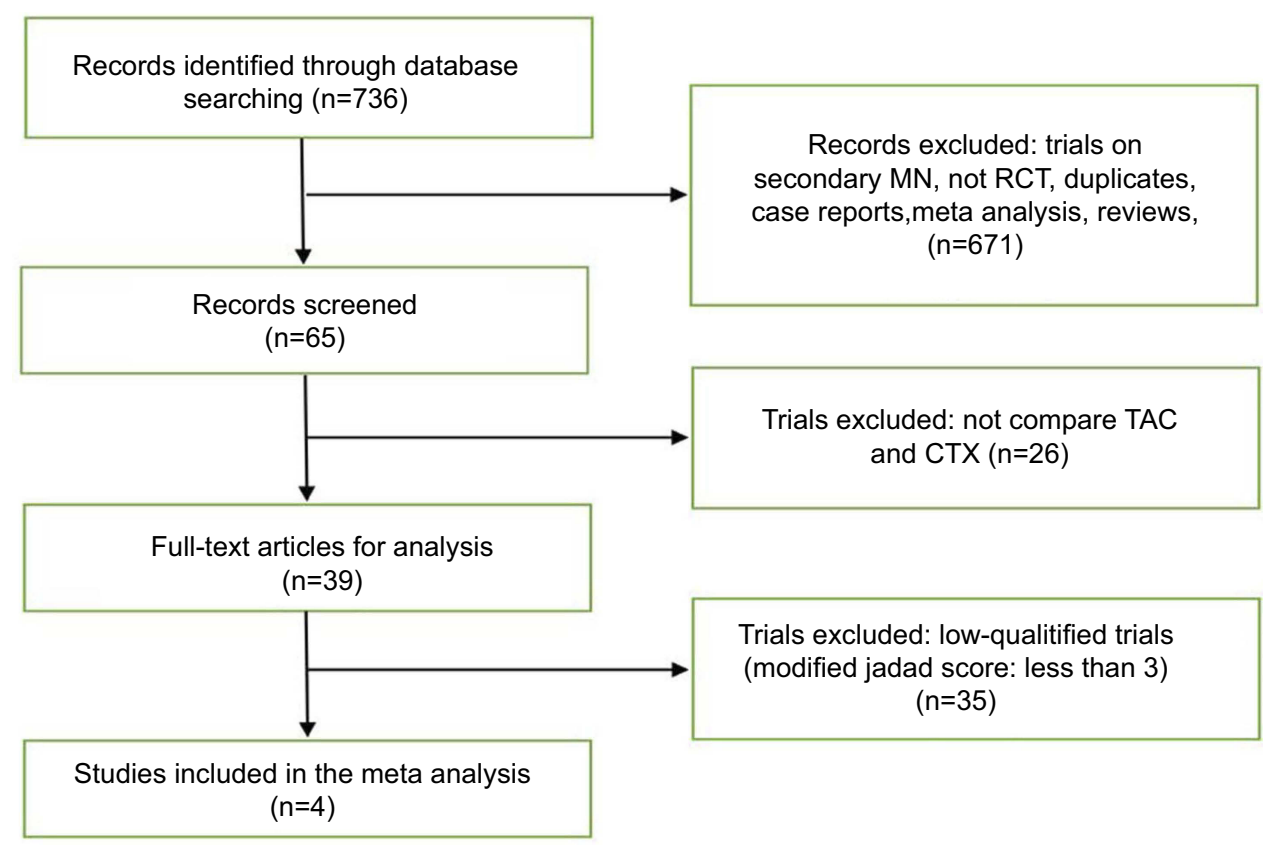

Figure I Flowchart of the selection process.

Abbreviations: MN, membranous nephropathy; RCT, randomized controlled trial; TAC, tacrolimus; CTX, cyclophosphamide. 
randomization with a table of random numbers and allocation concealment by enclosing assignments in opaque-closed envelopes, then again a detailed description of withdrawals and dropouts. The study from $\mathrm{He}$ et $\mathrm{al}^{11}$ scored 3 points, performing randomization through a preprinted randomization table and describing no withdrawals and dropouts during the trial. The trial from Ramachandran et al ${ }^{12,13}$ scored 5 points, performing randomization by following computerbased random numbers and allocation concealment by using sequentially labeled sealed envelopes, and giving a detailed account of withdrawals and dropouts as well. Characteristics of the studies included in this meta-analysis are shown in Table 1, and the details of quality assessment with Modified Jadad Scale are shown in Table 2.

\section{Assessment of complete remission}

Three studies $(\mathrm{n}=199)^{10-12}$ on 6-month CR and two studies $(n=126)^{11,12}$ on 12-month CR were included and the data were extracted. The results indicated that the TAC could get a better 6-month and 12-month CR when compared with CTX, although the difference was not statistically significant (6-month: $\mathrm{OR}=1.53$, 95\% CI: $0.85-2.76, \quad P=0.15$; 12month: $\mathrm{OR}=2.17,95 \% \mathrm{CI}$ : $0.56-8.44, P=0.27$; Figure 2 ).

\section{Assessment of total remission (TR; total CR plus $\mathrm{PR}$ )}

Three trials $(n=199)^{10-13}$ were included in the meta-analysis to assess the efficacy of TAC vs CTX in patients with IMN. Three studies $(\mathrm{n}=199)^{10-12}$ on 6-month TR, and two studies $(\mathrm{n}=126)^{11,12}$ on 12-month TR were included and the data were extracted. The results indicated that TAC could get a better TR on 6-month TR (OR=2.62, 95\% CI: 1.38-4.96, $P=0.003$; Figure 3). But no evidence was found for superiority between TAC and CTX on 12-month TR (OR=1.74, 95\% CI: 0.29-10.48, $P=0.54$; Figure 3).

\section{Assessment of relapse rate}

Three studies $(\mathrm{n}=199)^{10,11,13}$ were pooled for the assessment of relapse rate of TAC vs CTX. The results indicated that the difference of relapse rate between TAC group and CTX group was not notable $(\mathrm{OR}=2.53,95 \% \mathrm{CI}: 0.21-$ $30.06, P=0.46)$.

\section{Assessment of mean time to remission}

Two studies $(\mathrm{n}=126)^{11,12}$ were included for the assessment of mean time to remission of TAC vs CTX. The results indicated that TAC could get a shorter mean time to remission when compared with CTX, although the difference was not statistically significant $(\mathrm{OR}=-0.38,95 \% \mathrm{CI}$ : $-1.22-0.45, P=0.37)$.

\section{Assessment of proteinuria}

Three trials $(\mathrm{n}=199)^{10-12}$ were included for the assessment in reducing proteinuria of TAC vs CTX. Two studies $(\mathrm{n}=143)^{10,12}$ on 6 -month treatment and 3 trials $(\mathrm{n}=199)^{10-12}$ on 12-month treatment were included and the data were extracted. The results indicated that TAC could get a lower proteinuria on 6-month treatment when compared with CTX ( $\mathrm{OR}=-0.80,95 \% \mathrm{CI}:-1.53$ to $-0.07, P=0.03$ ). But there was no significant difference in reducing proteinuria between TAC group and CTX group on 12-month treatment $(\mathrm{OR}=$ $-0.47,95 \%$ CI: -1.85 to $0.90, P=0.50$ ).

\section{Assessment of albumin}

Three trials $(n=199)^{10-12}$ were included for the assessment of albumin of TAC vs CTX. Two trials $(n=143)^{10,12}$ on 6-month treatment and 3 trials $(n=199)^{10-12}$ on 12-month treatment were included and the data were analyzed. The results indicated that the TAC treatment could get a higher albumin on 6-month and 12-month treatment when compared with CTX treatment but without statistically significant difference (6-month: $\mathrm{OR}=1.27,95 \% \mathrm{CI}:-1.56$ to 4.10, $P=0.38 ; 12$-month: $\mathrm{OR}=2.28,95 \%$ CI: -3.22 to 7.79, $P=0.42$ ).

\section{Assessment of eGFR}

Two trials $(n=143)^{10,12}$ were included for the assessment of glomerular filtration rate of TAC vs CTX. The results indicated that the difference of glomerular filtration rate on 12-month treatment between two groups was not notable $(\mathrm{OR}=-1.81,95 \% \mathrm{CI}:-9.70$ to $6.08, P=0.65)$.

\section{Adverse effects}

The safety of TAC was also assessed in patients with IMN. In this meta-analysis, the incidence rate of leucopenia in TAC group was lower than those in CTX group $(\mathrm{OR}=0.11$, 95\% CI: $0.01-0.92, P=0.04)$, but the incidence rate of increased blood creatinine $(\mathrm{OR}=10.90,95 \% \mathrm{CI}: 1.41-$ 84.31, $P=0.02)$ and tremor $(\mathrm{OR}=8.29,95 \% \mathrm{CI}: 1.01-$ $67.85, P=0.05$ ) in TAC group were higher than those in CTX group. Besides, in this meta-analysis, the differences of incidence rate of gastrointestinal syndrome, infection, herpes zoster, hypertension, liver function disorder, hyperglycemia were not statistically significant. 


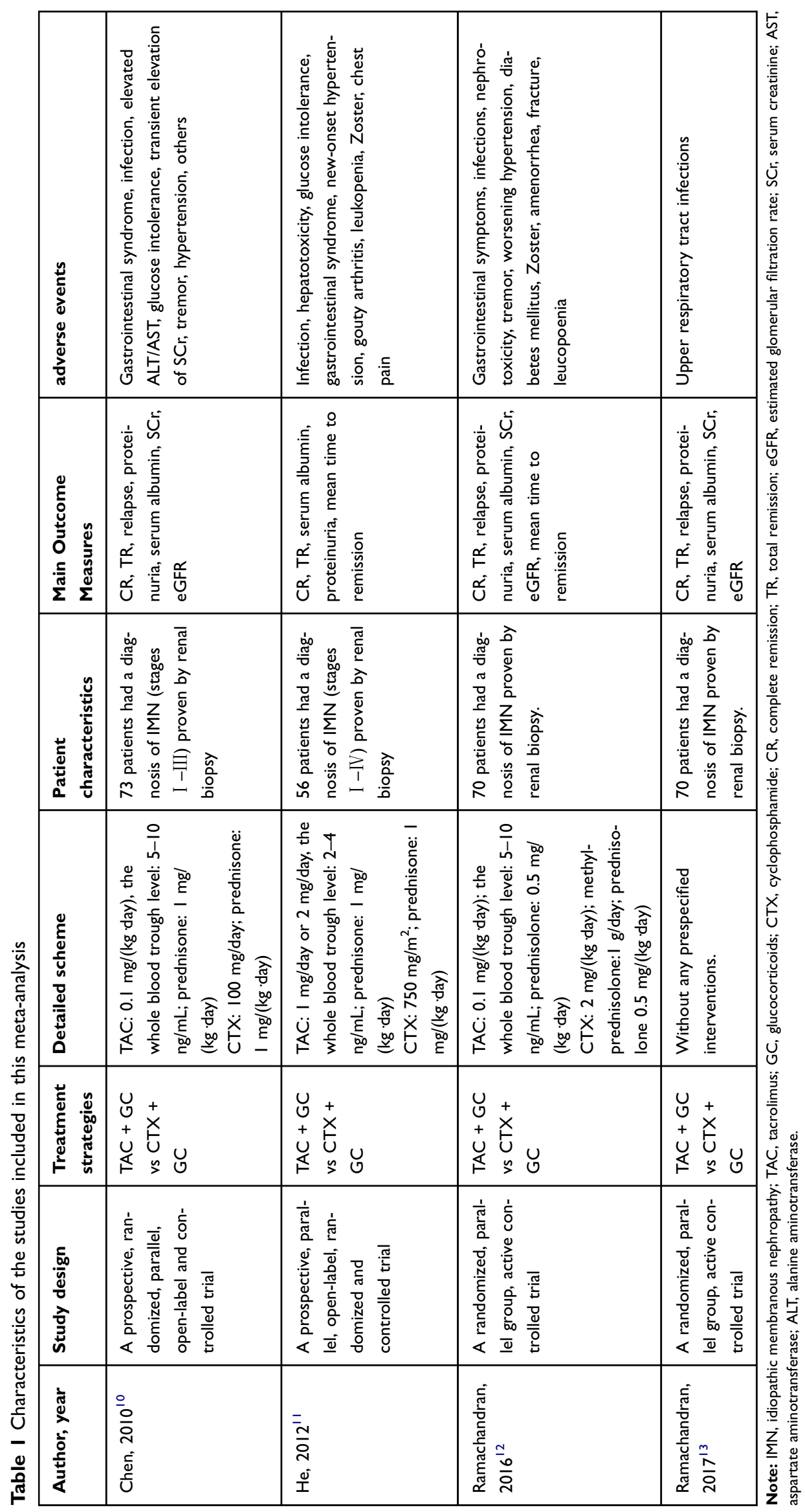


Table 2 Quality assessment of included studies (7-point)

\begin{tabular}{|c|c|c|c|c|c|c|}
\hline Author, year & Type & Randomization & $\begin{array}{l}\text { Concealment of } \\
\text { allocation }\end{array}$ & $\begin{array}{l}\text { Double } \\
\text { blinding }\end{array}$ & $\begin{array}{l}\text { Withdrawals } \\
\text { and dropouts }\end{array}$ & $\begin{array}{l}\text { Jaded } \\
\text { score }\end{array}$ \\
\hline $\begin{array}{l}\text { Chen, } 2010^{10} \\
(T A C+G C \text { vs } \\
\text { CTX + GC) }\end{array}$ & $\begin{array}{l}\text { A prospective, rando- } \\
\text { mized, parallel, open- } \\
\text { label and controlled trial }\end{array}$ & $\begin{array}{l}\text { By using a table } \\
\text { of random } \\
\text { numbers }\end{array}$ & $\begin{array}{l}\text { By enclosing assignments in } \\
\text { sequentially numbered, opa- } \\
\text { que-closed envelopes }\end{array}$ & Open-label & Yes & 5 \\
\hline $\begin{array}{l}\mathrm{He}, 2012^{11} \\
(\mathrm{TAC}+\mathrm{GC} \text { vs } \\
\text { CTX + GC) }\end{array}$ & $\begin{array}{l}\text { A prospective, parallel, } \\
\text { open-label, randomized } \\
\text { and controlled trial }\end{array}$ & $\begin{array}{l}\text { Through a pre- } \\
\text { printed randomi- } \\
\text { zation table }\end{array}$ & No available & Open-label & No & 3 \\
\hline $\begin{array}{l}\text { Ramachandran, } 2016^{12} \\
(T A C+G C \text { vs } \\
\text { CTX + GC) }\end{array}$ & $\begin{array}{l}\text { A randomized, parallel } \\
\text { group, active controlled } \\
\text { trial }\end{array}$ & $\begin{array}{l}\text { By following } \\
\text { computer-based } \\
\text { random numbers }\end{array}$ & $\begin{array}{l}\text { By using sequentially labelled } \\
\text { sealed envelopes }\end{array}$ & Open-label & Yes & 5 \\
\hline $\begin{array}{l}\text { Ramachandran, } 2017^{13} \\
(T A C+G C \text { vs } \\
\text { CTX + GC) }\end{array}$ & $\begin{array}{l}\text { A randomized, parallel } \\
\text { group, active controlled } \\
\text { trial }\end{array}$ & $\begin{array}{l}\text { By following } \\
\text { computer-based } \\
\text { random numbers }\end{array}$ & $\begin{array}{l}\text { By using sequentially labelled } \\
\text { sealed envelopes }\end{array}$ & Open-label & Yes & 5 \\
\hline
\end{tabular}

Abbreviations: TAC, tacrolimus; GC, glucocorticoids; CTX, cyclophosphamide.

\section{6-month}

\begin{tabular}{|c|c|c|c|c|c|c|c|c|}
\hline Study or subgroup & $\begin{array}{l}\mathrm{TAC}+\mathrm{C} \\
\text { Events }\end{array}$ & $\begin{array}{l}\text { GC } \\
\text { Total }\end{array}$ & $\begin{array}{l}\text { CTX+C } \\
\text { Events }\end{array}$ & Total & Weight & $\begin{array}{c}\text { Odds ratio } \\
\mathrm{M}-\mathrm{H}, \text { Fixed, } 95 \% \mathrm{Cl} \\
\end{array}$ & Year & $\begin{array}{c}\text { Odds ratio } \\
\text { M-H, Fixed, } 95 \% \mathrm{Cl}\end{array}$ \\
\hline Chen M 2010 & 11 & 39 & 9 & 34 & $4 \quad 38.2 \%$ & $1.09[0.39,3.07]$ & 2010 & \\
\hline He LY 2012 & 16 & 28 & 7 & 28 & $16.6 \%$ & $4.00[1.28,12.46]$ & 2012 & \\
\hline Ramachandran R 2016 & 13 & 35 & 13 & 35 & $45.2 \%$ & $1.00[0.38,2.64]$ & 2016 & \\
\hline Total $(95 \% \mathrm{Cl})$ & & 102 & & 97 & $100.0 \%$ & $1.53[0.85,2.76]$ & & \\
\hline Total events & 40 & & 29 & & & & & \\
\hline $\begin{array}{l}\text { Heterogeneity: } C h i^{2}=3.90 \\
\text { Test for overall effect: } Z=1\end{array}$ & $\begin{array}{l}d f=2(P=0 \\
.43(P=0.1\end{array}$ & $\begin{array}{l}0.14) ; I^{2} \\
15)\end{array}$ & $=49 \%$ & & & & & \begin{tabular}{|lllll}
0.01 & 0.1 & 1 & 10 & 100 \\
Favours & $T A C+G C$ & Favours & CTX+GC
\end{tabular} \\
\hline Studv or subgroup & $\begin{array}{l}\text { TAC+GC } \\
\text { Events }\end{array}$ & Total & $\begin{array}{l}\text { CTX+GC } \\
\text { Events }\end{array}$ & Total & Weight & $\begin{array}{l}\text { Odds ratio } \\
\text { M-H. Random, } 95 \% \mathrm{Cl}\end{array}$ & Year & $\begin{array}{l}\text { Odds ratio } \\
\text { M.H. Random, } 95 \% \mathrm{Cl}\end{array}$ \\
\hline He LY 2012 & 18 & 28 & 8 & 28 & $47.4 \%$ & $4.50[1.46,13.89]$ & 2012 & \\
\hline Ramachandran R 2016 & 19 & 35 & 18 & 35 & $52.6 \%$ & $1.12[0.44,2.87]$ & 2016 & \\
\hline Total $(95 \% \mathrm{Cl})$ & & 63 & & 63 & $100.0 \%$ & $2.17[0.56,8.44]$ & & \\
\hline Total events & 37 & & 26 & & & & & \\
\hline \multicolumn{8}{|c|}{$\begin{array}{l}\text { Heterogeneity. } \operatorname{Tau}^{z}=0.69 ; C h^{z}=3.45, d f=1 \quad(P=0.06) ; I^{z}=71 \% \\
\text { Test for overall effect: } Z=1.11(P=0.27)\end{array}$} & $\begin{array}{ccccc}0.01 & 0.1 & 1 & 10 & 100 \\
\text { Favours } & T A C+G C & \text { Favours } C T X+G C\end{array}$ \\
\hline
\end{tabular}

Figure 2 Assessment of complete remission of TAC vs CTX.

Abbreviations: GC, glucocorticoids; TAC, tacrolimus; CTX, cyclophosphamide; M-H, Mantel-Haenszel.

\section{Discussion}

Besides alkylating agents and calcineurin inhibitors, several kinds of medications, such as mycophenolate mofetil, rituximab, Tripterygium wilfordii, adrenal cortex hormone and GC, were also mentioned in the KDIGO 2012 guidelines, but further studies and clinical trials of them are required for the limited studies and small sample size. ${ }^{4}$ In this metaanalysis, we try to find out a better therapeutic option for IMN by comparing CTX with TAC, which is the surrogate of the alkylating agents and calcineurin inhibitors separately. Therefore, we included all patients regardless of race with IMN but excluded the low-qualified studies to refrain from precluding the exact conclusions.
TAC has been found to exert its immunosuppressive effect via formulating complex with a particular immunophilin called FK-506-binding protein 12 to inhibit calcineurin phosphatase which can activate the nuclear factor of activated $\mathrm{T}$ cells for the consecutive transcription of cytokines like IL-2, IFN- $\gamma$. Consequently, the growth and differentiation of leukomonocytes are baffled with a loss of inflammatory factors. ${ }^{14}$ In this way, there is a decrease in formation of subeptithelial immune deposits and protection for podocytes. With regard to CTX, it not only induces cell apoptosis by crosslinking the DNA strands for an antineoplastic effect, but inhibits the activations of both T- and B-lymphocytes, especially decreasing the antibody produced by B cells. ${ }^{15}$ 


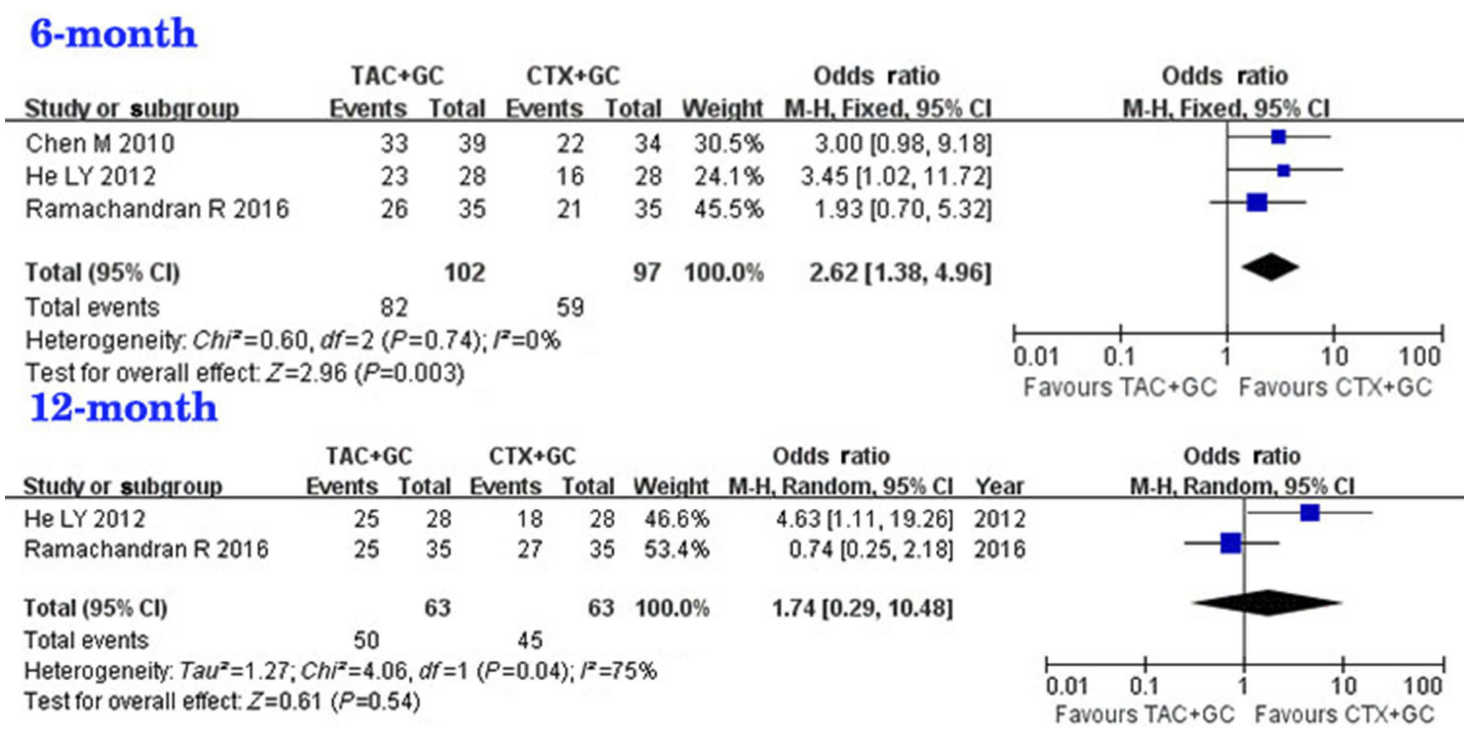

Figure 3 Assessment of total remission of TAC vs CTX.

Abbreviations: GC, glucocorticoids; TAC, tacrolimus; CTX, cyclophosphamide; $M-H$, Mantel-Haenszel.

A recently published study by Zhu et $\mathrm{al}^{16}$ including 6 controlled clinical trials comparing TAC/GC with CTX/ GC reported that TAC had a much better effect on inducing remission than CTX during the early follow-up, although the reverse results were found after 1 year. Another meta-analysis showed that both 6-month CR and TR in TAC group were significantly higher than those in CTX group ${ }^{9}$ (RR=1.731, 95\% CI: $1.253-2.390$, $P=0.001 ; \mathrm{RR}=1.193,95 \%$ CI: $1.044-1.365, P=0.010$ ). The data analyzed by Thapa et al ${ }^{17}$ suggested that TAC group could get a better CR than CTX group at 6-month treatment, and the difference was statistically significant $(\mathrm{RR}=1.53,95 \% \mathrm{CI}: 1.05-2.24, P=0.03)$. In general, these studies suggested that TAC was able to get a better effect than CTX in inducing early remission, with which this present study coincided. In this meta-analysis, the results indicated that TAC group had high values of TR and had a significant reduction in proteinuria levels when compared with those in CTX group on 6-month treatment. What is more, we also compared the CR and albumin on 6-month and 12-month treatment, TR and proteinuria on 12-month treatment, the relapse rate, glomerular filtration rate, serum creatinine and mean time to remission between TAC group and CTX group. The results seemed to stand by the side of TAC, but the difference was not notable. Concerning to the safety of two drugs, Zhu et a ${ }^{16}$ found that the incidence of leukopenia in CTX group was significantly higher, while a tendency toward a higher rate of tremor was observed in TAC group; but no statistically significant difference on adverse reactions was reported by Li et $\mathrm{al}^{16}$ and Thapa et $\mathrm{al}^{17}$. In this meta-analysis for adverse events, the group treated with TAC had a significant lower risk of leucopenia than the CTX group. However, the incidence rates of increased blood creatinine and tremor in TAC group were higher than those in CTX group. The differences of incidence rates of gastrointestinal syndrome, infection, herpes zoster, hypertension, liver function disorder, hyperglycemia were not notable. It might tell us that TAC might be an effective and safe agent to treat the IMN.

Modified Jadad Scale was used in this study to score the trials, and the studies with high quality were pooled to analyze for convincing results. In this meta-analysis, we only included the trails with high quality for meta-analysis. The results from our meta-analysis might be more robust than other meta-analyses mentioned above. However, with a small sample size, caution must be applied, as the results might not be inadequate to appropriately assess the accuracy. Therefore, this result should be drawn with careful deliberation.

In our meta-analysis, we found that TAC treatment could get high value of TR and had low value of proteinuria level when compared with those in CTX treatment on 6-month treatment, indicating that TAC was able to get a better effect than CTX in short-term efficacy. It is hard to say which regimen is safer. As an old saying goes, one person's poison is another man's cure. Under the principle of individualized treatment, whichever should be 
reasonably selected. However, larger high-quality RCTs are also needed to confirm it in the future.

\section{Acknowledgments}

This study was supported by the Guangzhou Medical Key Discipline Construction Project, the Natural Science Foundation of the Guangdong Province (no. 2015A030310386) and Guangdong Medical Science and Technology Research Fund Project (no. A2018336).

\section{Disclosure}

The authors report no conflicts of interest in this work.

\section{References}

1. Debiec H, Ronco P. Immunopathogenesis of membranous nephropathy: an update. Semin Immunopathol. 2014;36:381-397. doi:10.1007/ s00281-014-0423-y

2. Wasserstein AG. Membranous glomerulonephritis. J Am Soc Nephrol. 1997;8:664-674.

3. Thompson A, Cattran DC, Blank M, Nachman PH. Complete and partial remission as surrogate end points in membranous nephropathy. $J$ Am Soc Nephrol. 2015;26:2930-2937. doi:10.1681/ASN.2015010091

4. Chapter 7: idiopathic membranous nephropathy. Kidney Int Suppl. 2012;2:186-197. doi:10.1038/kisup.2012.20

5. Praga M, Barrio V, Juarez GF, et al. Tacrolimus monotherapy in membranous nephropathy: a randomized controlled trial. Kidney Int. 2007;71:924-930. doi:10.1038/sj.ki.5002215

6. Cattran DC, Appel GB, Hebert LA, et al. Cyclosporine in patients with steroid-resistant membranous nephropathy: a randomized trial. Kidney Int. 2001;59:1484-1490. doi:10.1046/j.1523-1755.2001.0590041484.x

7. Mccauley J, Tzakis AG, Fung JJ, et al. FK506 in steroid-resistant focal sclerosing glomerulonephritis of childhood. Lancet. 1990; 335:674. doi:10.1016/0140-6736(90)90471-g
8. Shen X, Hong J, Ying M, et al. Calcineurin inhibitors cyclosporin A and tacrolimus protect against podocyte injury induced by puromycin aminonucleoside in rodent models. Sci Rep. 2016;6:32087. doi: $10.1038 /$ srep32087

9. Li ZQ, Hu ML, Zhang C, et al. Efficacy and safety of tacrolimus vs. cyclophosphamide for idiopathic membranous nephropathy: a meta-analysis of Chinese adults. J Huazhong Univ Sci Technolog Med Sci. 2015;35:623-628. doi:10.1007/s11596-015-1480-8

10. Chen M, Li H, Li XY, et al. Tacrolimus combined with corticosteroids in treatment of nephrotic idiopathic membranous nephropathy: a multicenter randomized controlled trial. $\mathrm{Am} J$ Med Sci. 2010;339:233-238. doi:10.1097/MAJ.0b013e3181ca3a7d

11. He L, Peng Y, Liu H, et al. Treatment of idiopathic membranous nephropathy with combination of low-dose tacrolimus and corticosteroids. J Nephrol. 2013;26:564-571. doi:10.5301/jn.50001 99

12. Ramachandran R, Hn HK, Kumar V, et al. Tacrolimus combined with corticosteroids versus Modified Ponticelli regimen in treatment of idiopathic membranous nephropathy: randomized control trial. Nephrology (Carlton). 2016;21:139-146. doi:10.1111/ nep. 12569

13. Ramachandran R, Yadav AK, Kumar V, et al. Two-year follow-up study of membranous nephropathy treated with tacrolimus and corticosteroids versus cyclical corticosteroids and cyclophosphamide. Kidney Int Rep. 2017;2:610-616. doi:10.1016/j.ekir.2017. 02.004

14. Westhoff TH, van der Giet M. Tacrolimus in the treatment of idiopathic nephrotic syndrome. Expert Opin Investig Drugs. 2007;16:1099-1110. doi:10.1517/13543784.16.7.1099

15. Ponticelli C, Escoli R, Moroni G. Does cyclophosphamide still play a role in glomerular diseases? Autoimmun Rev. 2018;17:1022-1027. doi:10.1016/j.autrev.2018.04.007

16. Zhu LB, Liu LL, Yao L, et al. Efficacy and safety of tacrolimus versus cyclophosphamide for primary membranous nephropathy: a meta-analysis. Drugs. 2017;77:1-13. doi:10.1007/s40265-0160675-z

17. Santosh T, Hong L, Cheng LB. Effect of tacrolimus in idiopathic membranous nephropathy: a meta-analysis. Chin Med J (Engl). 2014;127:2693-2699.
Drug Design, Development and Therapy

\section{Publish your work in this journal}

Drug Design, Development and Therapy is an international, peerreviewed open-access journal that spans the spectrum of drug design and development through to clinical applications. Clinical outcomes, patient safety, and programs for the development and effective, safe, and sustained use of medicines are a feature of the journal, which has also

\section{Dovepress}

been accepted for indexing on PubMed Central. The manuscript management system is completely online and includes a very quick and fair peer-review system, which is all easy to use. Visit http://www. dovepress.com/testimonials.php to read real quotes from published authors. 